\title{
VARIABILIDADE ESPACIAL DOS PERCENTIS 75 DA PRECIPITAÇÃO PLUVIAL MENSAL NO ESTADO DO ESPÍRITO SANTO
}

Julião Soares de Souza Lima', Samuel de Assis Silva², Paula Mauri Bernardes ${ }^{3}$, Abel Souza da Fonseca ${ }^{3}$, João Marcelo Soares Pereira ${ }^{4}$

\section{RESUMO}

Conhecer a quantidade, intensidade e a distribuição espacial da precipitação pluvial contribuem para o gerenciamento de ações em vários setores da atividade humana. Nesse trabalho objetivou-se estudar a variabilidade espacial da precipitação no estado do Espírito Santo para cada mês, utilizando postos de observações da Agência Nacional de Águas (ANA), com intervalos de observações de 25 a 70 anos. Ao analisar a série de precipitação pluvial mensal constatou-se a presença de elevada amplitude total nos dados. Sendo assim, optou-se em trabalhar com o valor dos percentis 75 da série em cada mês como a maior precipitação, evitando informar anomalias climáticas. Os dados foram analisados pela estatística clássica determinando as medidas de posição e dispersão. Na sequência utilizou a geoestatística para definição de semivariogramas e a construção de mapas da distribuição espacial da precipitação em cada mês, utilizando a krigagem ordinária. Os meses com menor ocorrência do percentil 75, definindo a estação de seca, foram de abril a setembro. Os percentis 75 da precipitação pluvial mensal apresenta forte dependência espacial, com exceção no mês de janeiro, sendo que os alcances de dependência espacial variam de 41,6 a 210,6 km entre os meses. A distribuição espacial dos percentis 75 da precipitação pluvial evidenciou diferentes microclimas no estado, mostrando que os municípios que compõem a região noroeste tem menor ocorrência de precipitação, principalmente no mês de junho. O mês de dezembro, novembro e janeiro apresentam maiores lâminas de precipitação pluvial.

Palavras-chave: geoestatística, postos pluviométricos, semivariograma

\section{ABSTRACT \\ SPATIAL VARIABILITY OF MONTHLY 75 PERCENTIL PRECIPITATION FOR ESPÍRITO SANTO STATE - BRAZIL}

Knowing the amount, intensity and spatial distribution of rainfall contribute to management actions in various sectors of human activity. This work aimed to study the spatial variability of rainfall in the state of the Espírito Santo- Brazil for each month using observation stations of the National Water Agency (NWA), with intervals of observations of 25 to 70 years. By analyzing the monthly precipitation series found the presence of high total amplitude in the data. And thus it was decided to work with the value of the percentiles 75 series each month as the highest rainfall, preventing inform climate anomalies. Data were analyzed by classical statistic measures determining the position and dispersion. Following used geostatistics to define semivariograms and construction of maps of the spatial distribution of rainfall in each month, using the ordinary kriging. The months with minor occurrences of the percentile 75 , setting the dry season, were from april to september. Percentiles 75 Monthly rainfall has strong spatial dependence, except in january, and the spatial dependence ranges vary from 41.6 to $210.6 \mathrm{~km}$ between the months. The spatial distribution of percentiles 75 of rainfall showed different microclimates in the state, showing that the municipalities that make up the northwest region has the lowest rainfall, especially in June. The months december, november and january have greater height of rainfall.

Keywords: geostatistics, pluviometric stations, semivariograms

\author{
Recebido para publicação em 16/05/2016. Aprovado em 26/09/2016. \\ 1 - Engenheiro Agrícola, Professor Titular da UFES/Alegre-ES, limajss@yahoo.com.br \\ 2 - Engenheiro Agrônomo, Professor Adjunto I da UFES/Alegre-ES \\ 3 - Engenheiro Agrônomo, Doutorando da UFES/Alegre-ES \\ 4 - Engenheiro Civil, Mestrando da UFES/Alegre-ES
}




\section{INTRODUÇÃO}

Conhecer a variabilidade espacial e temporal da precipitação pluviométrica mensal e acumulada no ano vem mostrando ser cada vez mais importante, uma vez que é o regime pluviométrico que determina a maioria das atividades desenvolvidas numa região (LOPES et al., 2014).

Mello et al. (2012) afirmam que o mapeamento da distribuição espacial de variáveis climáticas constitui-se em ferramenta indispensável ao planejamento de atividades relacionadas, principalmente, à agricultura e mineração. No seu estudo, foi mapeada a erosividade da chuva para o estado do Espirito Santo distinguindo dois períodos específicos, um chuvoso e outro seco. Uliana et al. (2013) também identificaram dois períodos distintos da ocorrência da precipitação no estado do Espirito Santo.

A variabilidade espacial e temporal da precipitação de uma região está diretamente ligada ao seu relevo, ou seja, à sua orografia e que a tendência pluviométrica deve ser analisada buscando-se entender a ocorrência da precipitação em determinada região e associá-la a processos naturais e sociais (ANDRADE et al., 2011). Silva e Lima (2011) estudaram a distribuição espacial da precipitação pluvial média do estado do Espirito Santo considerando a altitude dos postos pluviométricos e definiram o número de postos necessários para mapear a precipitação no estado considerando a dependência espacial.

A análise da ocorrência de precipitações intensas para o estado do Espirito Santo foi abordada por Senna et al. (2010), uma vez que estes eventos estão relacionados com os processos erosivos em função do grande volume precipitado em um pequeno intervalo de tempo. De acordo com Melo Junior et al. (2006), a chuva é um dos elementos climáticos mais diretamente relacionados à produção agrícola, devido ao seu caráter aleatório, aumentando os riscos na programação das atividades do setor.

Como existe considerável variabilidade espacial e temporal na precipitação pluviométrica, estimativas baseadas na média aritmética podem não apresentar precisão e confiabilidade, podendo levar a valores distorcidos (BLAIN et al., 2007; LIMA et al., 2008). Mousinho et al. (2006) comentam que estudos utilizando a média da precipitação não apresentam resultados consistentes já que a probabilidade de ocorrência da média é de apenas $50 \%$, justificando-se assim o uso de probabilidades não inferiores a $75 \%$.

O estudo do clima é normalmente realizado por meio da análise da variabilidade espaço-temporal dos elementos meteorológicos observados em uma região (BLAIN et al., 2009). Conhecer os diversos elementos do clima é de extrema importância, tendo em vista o impacto ambiental causado pelas anomalias climáticas em decorrência da variação do regime da chuva, embora o regime térmico também possa ser modificado e influenciar o meio ambiente (BRITTO et al., 2008).

A variabilidade climática anual é bem caracterizada e está associada às estações do ano, que em latitudes médias é marcante o contraste entre elas, porém, nos trópicos essa variabilidade é menos acentuada em termos da temperatura, sendo expressiva quando se considera a precipitação pluvial (GURGEL, 2003) apud Sartori et al. (2010). O conhecimento da distribuição temporal das variáveis climáticas contribui para o estudo e o zoneamento agroclimático (SARTORI et al., 2010).

Definido o padrão de distribuição espacial de um atributo estima-se por meio de métodos de interpolação valores para locais não amostrados, o que permite identificar regiões com diferentes microclimas auxiliando na tomada de decisão. Neste contexto, este trabalho teve por objetivo determinar as estações de seca e de chuva e a variabilidade espacial dos percentis 75 da precipitação pluvial mensal para o estado do Espírito Santo utilizando técnicas de estatística clássica e geoestatística.

\section{MATERIAL E MÉTODOS}

Os dados de precipitação pluvial utilizados neste estudo foram obtidos junto à Agência Nacional de Águas (ANA), e compreendem de 25 a 70 anos de precipitação nos municípios do estado do Espírito Santo, totalizando 55 postos pluviométricos (Figura 1). 

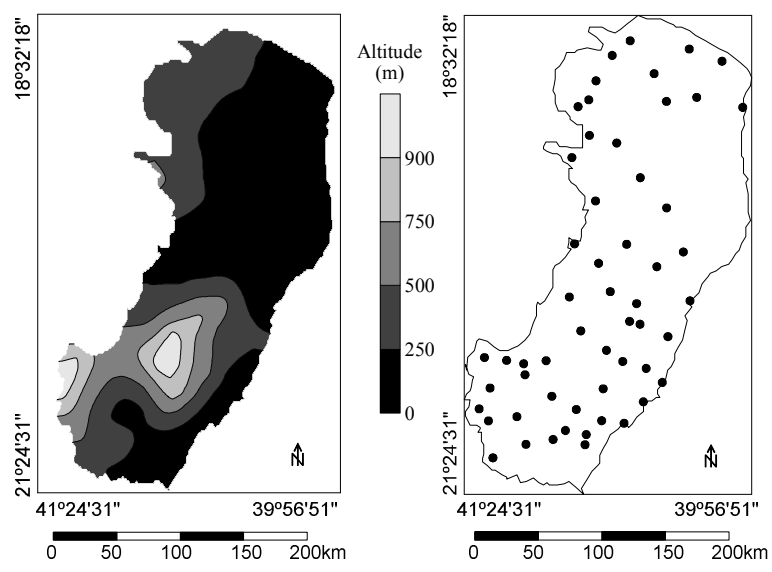

Figura 1. Mapa da distribuição espacial da altitude e da localização dos postos pluviométricos.

A topografia do estado do Espírito Santo é composta por áreas montanhosas no seu interior e planas no litoral. Segundo sistema de classificação de Köppen, apresenta as zonas climáticas A e C, classificadas como climas úmidos. Encontram-se os seguintes subtipos climáticos: Aw, $\mathrm{Am}, \mathrm{Cf}$ e $\mathrm{Cw}$, e as variações $\mathrm{Cfa}, \mathrm{Cfb}$, Cwa e $\mathrm{Cwb}$.

As estações (postos de amostragens) foram selecionadas, segundo critérios de Nery e Aves (2009), baseando-se na melhor distribuição espacial e temporal, considerando-se também que não apresentassem falhas consideráveis ao longo dessas séries. As observações referemse às precipitações pluviais diárias acumuladas mensalmente e expressas em altura de lâmina d'água $(\mathrm{mm})$. Os dados foram avaliados levandose em conta todo o período de medição anual e mensal (já realizados os procedimentos de análise de consistência e de preenchimento de falhas).

As análises iniciais têm por propósito verificar a variabilidade e caracterizar a distribuição de probabilidade, baseada na análise descritiva dos dados da precipitação pluvial mensal, sendo obtidos: média; mediana; desvio-padrão; valor mínimo e máximo; percentil 25 (Q1), percentil 75 (Q3), os coeficientes de variação, assimetria e curtose.

A normalidade dos dados foi testada pelo método Shapiro-Wilk's que é um método não paramétrico de aderência à distribuição normal. Os testes existentes têm estatísticas de teste e critérios de decisão diferentes, entretanto têm em comum as hipóteses testadas: a hipótese de nulidade é de que a variável aleatória adere à distribuição normal, contra a hipótese alternativa de que a variável aleatória não adere à distribuição normal (TORMAN et al. (2012).

Em uma análise prévia dos dados, foi constatada amplitude total elevada em cada mês do ano, tendo em pelo menos um mês e em determinado ano ocorrência de ausência de precipitação, bem como valores extremos de elevada ocorrência de precipitação. Com base nas afirmações anteriores e da ocorrência de elevada variação na amplitude total, decidiu-se trabalhar com o valor dos percentis 75 da série de precipitação pluvial para cada mês, ou seja, com $75 \%$ das ocorrências de precipitação mensal evitando, assim, informar anomalias climáticas.

$\mathrm{Na}$ definição das estações de seca e de chuva, considerou-se o método descrito por Nery et al. (2002) que considera a porcentagem da contribuição da média de cada mês em relação à precipitação média acumulada anual. Segundo esses autores é importante observar que se todos os meses do ano contribuíssem igualmente com precipitação mensal em relação ao acumulado durante o ano, teríamos uma contribuição de $1 / 12$ do total anual $(8,33 \%)$ e, assim, mês de seca para valores mensais menores que esse.

A análise geoestatística foi utilizada para definir o modelo de variabilidade espacial dos percentis 75 da precipitação pluvial mensal para o estado do Espirito Santo. Adependência espacial foi analisada por meio de ajuste de semivariogramas teóricos, com base nas pressuposições de estacionaridade da hipótese intrínseca, estimado pela equação 1 :

$\gamma(\mathrm{h})=\frac{1}{2 N(\mathrm{t})} \sum_{\mathrm{i}=1}^{\mathrm{N}(\mathrm{h})}[\mathrm{Z}(\mathrm{x})-\mathrm{Z}(\mathrm{x}+\mathrm{h})]^{2}$

em que,

$\gamma(\mathrm{h})=$ semivariância para um vetor $\mathrm{h} ; \mathrm{Z}(\mathrm{x}) \mathrm{e}$ $\mathrm{Z}(\mathrm{x}+\mathrm{h})=$ pares de observações de precipitação pluviométrica; e

$\mathrm{N}(\mathrm{h})=$ número de pares de valores medidos.

Os modelos teóricos testados nos ajustes dos 
semivariogramas foram o esférico, o exponencial e o gaussiano. O melhor ajuste foi com base na menor soma do quadrado dos resíduos e o maior coeficiente de determinação $\left(\mathrm{R}^{2}\right)$. Considerou-se também o coeficiente de correlação da validação cruzada, entre os valores observados e os estimados, na escolha final do modelo do semivariograma.

Conforme critérios estabelecidos por Zimback (2001) o índice de dependência espacial (IDE) assume os seguintes intervalos: fraco para valores de IDE $<25 \%$; moderado entre $25 \% \leq$ IDE $\leq 75 \%$ e forte para IDE $>75 \%$.

Observada a existência de dependência espacial, estimaram-se valores para locais onde a variável não foi medida, utilizando-se a krigagem ordinária (KO), quantificada por um semivariograma, como método interpolador. Segundo Yamamoto e Landim (2013) a KO é um método de estimativa linear não enviesado e pode ser aplicado em diversas áreas do conhecimento. $\mathrm{O}$ estimador da $\mathrm{KO}$ é baseado na fórmula da média ponderada, onde os ponderadores dependem da informação estrutural fornecida pelo semivariograma. Esta é a principal diferença em relação ao outros métodos de estimativa como, por exemplo, o inverso da distância.

Para o cálculo da interpolação do valor de um ponto por meio do método de krigagem ordinária, utiliza-se a equação 2 , conforme apresentado em Marcuzzo et al. (2011).

$\mathrm{Z}\left(\mathrm{x}_{0}\right)=\frac{\sum_{1=1}^{\mathrm{n}} \omega_{\mathrm{i}} \mathrm{Z}\left(\mathrm{x}_{\mathrm{i}}\right)}{\sum_{\mathrm{i}=1}^{\mathrm{n}} \omega_{\mathrm{i}}}$

em que,

$\mathrm{Z}\left(\mathrm{x}_{0}\right)=$ valor do ponto que se deseja interpolar; $\mathrm{n}=$ quantidade de pontos amostrados cujos valores serão usados na interpolação do ponto $\mathrm{x}$;

$\mathrm{Z}\left(\mathrm{x}_{\mathrm{i}}\right)=$ valor do ponto amostrado; $\mathrm{e}$

$\omega_{\mathrm{i}}=$ peso do valor de $\mathrm{Z}\left(\mathrm{x}_{\mathrm{i}}\right)$ sobre o ponto $\mathrm{x}$.

Marcuzzo et al. (2010) compararam os métodos de interpolação krigagem e spline de tensão para estimar a precipitação no entorno do município de Goiânia. Segundo os autores, em grande maioria dos casos o método de spline de tensão, que usa uma função matemática que minimiza a curvatura da superfície, resulta na suavização das isolinhas por passar exatamente pelos pontos de entrada, o que leva a produzir maior número de isolinhas em comparação com a krigagem. Este fato dificultou a interpretação e gerou inconsistências em alguns mapas. A krigagem, por sua vez, apresentou melhores resultados, pois o nível de detalhamento, ou isolinhas, apesar de ter sido menor manteve a qualidade da espacialização, facilitando a visualização das zonas de precipitação.

Após a estimativa dos dados, foram obtidos mapas da distribuição espacial da precipitação pluvial dos percentis 75 para cada mês no estado do Espírito Santo, em pixel de 1x1 km.

\section{RESULTADOS E DISCUSSÃO}

Os dados da análise descritiva da precipitação pluvial nos postos de observação da ANA no estado do Espírito Santo, para cada mês, estão apresentados no Quadro 1.

O menor valor médio de precipitação foi encontrado no mês de junho com $37,6 \mathrm{~mm}$ e o maior no mês de dezembro (208,4 mm). Verificase que em todos os meses ocorreu ausência de precipitação em pelo menos um ano da série de dados, indicando como mencionado anteriormente de elevada amplitude total na distribuição dos dados.

Valores de CVs (coeficientes de variação) menores que $60 \%$ ocorreram somente para os meses de novembro e dezembro. Os maiores valores de $\mathrm{CV}$ estão nos meses característicos de seca no estado: abril, maio, junho, julho, agosto e setembro. Mousinho et al. (2006) encontraram CV de $31,3 \%$ para os percentis 75 da precipitação pluvial anual para o estado do Piauí.

$\mathrm{O}$ coeficiente de assimetria (Cs) apresentou valor positivo, com a média de precipitação mensal maior que a mediana, com concentração de valores abaixo do valor médio. Para a curtose, a distribuição foi leptocurtica com $\mathrm{C}_{\mathrm{k}}$ positivo, com valores em torno da média. Tais valores indicam afastamento dos dados do padrão da curva de distribuição normal, o que foi confirmado pelo teste de Shapiro-Wilk's a 5\% de probabilidade. Cargnelutti Filho et al. (2010) em estudo no Rio Grande do Sul e Lima et al. (2008) no município de Alegre-ES, encontraram distribuição normal para 
Quadro 1. Estatísticas da precipitação pluvial mensal (mm) para o estado do Espírito Santo

\begin{tabular}{|c|c|c|c|c|c|c|c|c|c|c|c|c|}
\hline Mês & M & $\mathrm{Md}$ & $\frac{\mathrm{PM}}{\mathrm{PA}}(\%)$ & $\frac{\mathrm{PM} 75}{\mathrm{PA} 75}(\%)$ & Min & Máx & $\mathrm{S}$ & $\mathrm{C}_{\mathrm{s}}$ & $\mathrm{C}_{\mathrm{k}}$ & $\mathrm{P}_{25}$ & $\mathrm{P}_{75}$ & $\mathrm{CV}(\%)$ \\
\hline Jan & 174,0 & 152,8 & 13,9 & 14,1 & 0,0 & 838,5 & 126,0 & 1,1 & 1,4 & 76,5 & 239,7 & 72,4 \\
\hline Fev & 103,2 & 87,1 & 7,9 & 8,5 & 0,0 & 545,2 & 78,1 & 1,3 & 2,4 & 43,4 & 144,3 & 75,6 \\
\hline Mar & 138,0 & 119,9 & 10,9 & 11,0 & 0,0 & 962,2 & 99,3 & 1,4 & 3,7 & 63,9 & 187,5 & 71,9 \\
\hline Abr & 88,5 & 75,8 & 6,9 & 7,0 & 0,0 & 745,8 & 60,5 & 1,6 & 6,3 & 44,3 & 119,8 & 68,4 \\
\hline Mai & 55,2 & 44,8 & 4,1 & 4,4 & 0,0 & 563,5 & 46,5 & 2,3 & 10,6 & 22,7 & 74,8 & 84,4 \\
\hline Jun & 37,6 & 25,6 & 2,3 & 2,9 & 0,0 & 357,4 & 38,9 & 2,5 & 9,9 & 12,4 & 50,0 & 103,7 \\
\hline Jul & 46,4 & 32,4 & 3,0 & 3,7 & 0,0 & 423,0 & 46,9 & 2,1 & 6,9 & 14,2 & 63,0 & 101,0 \\
\hline Ago & 38,5 & 28,0 & 2,5 & 3,3 & 0,0 & 299,6 & 37,7 & 1,8 & 4,5 & 10,6 & 55,8 & 97,9 \\
\hline Set & 61,7 & 49,4 & 4,5 & 5,1 & 0,0 & 527,1 & 52,5 & 1,6 & 4,5 & 22,4 & 87,0 & 85,1 \\
\hline Out & 113,6 & 104,1 & 9,5 & 9,2 & 0,0 & 626,3 & 70,2 & 0,8 & 1,1 & 59,6 & 157,0 & 61,8 \\
\hline Nov & 195,6 & 183,8 & 16,7 & 14,9 & 0,0 & 888,5 & 101,5 & 0,9 & 1,7 & 120,6 & 253,6 & 51,9 \\
\hline Dez & 208,4 & 194,8 & 17,7 & 15,9 & 0,0 & 848,6 & 102,5 & 0,8 & 1,6 & 133,7 & 270,1 & 49,28 \\
\hline
\end{tabular}

M: média; Md: mediana; PM/PA: relação entre a precipitação média mensal e a média acumulada anual; PM75/PA75: relação entre percentil 75 mensal e o percentil 75 anual acumulado; Min: valor mínimo pluviométrico; Máx: valor máximo pluviométrico; $\mathrm{S}$ : desvio padrão; $\mathrm{C}_{\mathrm{S}}$ : coeficiente de assimetria; $\mathrm{C}_{\mathrm{k}}$ : coeficiente de curtose; $\mathrm{P}_{25}$ percentil $25 ; \mathrm{P}_{75}$ percentil 75 ; e $\mathrm{CV}$ : coeficiente de variação $(\%)$

os dados de precipitação pluvial mensal e anual, respectivamente.

A alta variabilidade apresentada na precipitação pluvial em todos os meses é fator decisivo para o não atendimento da distribuição normal, o que é provocado pela ausência e/ou baixa precipitação nos meses de seca e nos de chuva ou mesmo altos índices pluviométricos provenientes de algum evento climático atípico. Lopes et al. (2012) afirmam que na estação de seca as massas de ar equatorial continental deixam de atuar e permite a ação da massa tropical atlântica, que apresenta baixa umidade, ocorrendo neste período a diminuição da precipitação, no seu estudo para Goiás.

As estações do ano foram definidas pela relação entre a precipitação média mensal e a média acumulada anual (PM/PA) e pelo percentil 75 mensal e o percentil 75 acumulado anual (PM75/ PA75) menor ou maior que $8,33 \%$ (Figura 2). Os meses da estação de seca pelas duas relações são: fevereiro, abril, maio, junho, julho, agosto e setembro, respectivamente, com exceção para o mês de fevereiro que pela relação PM75/PA75 figura na estação chuvosa.
As atividades agrícolas, florestais e pecuárias que são desenvolvidas no estado nesses meses com restrição de ocorrência de precipitação devem ser conduzidas com um planejamento bem elaborado levando em conta a adversidade climática apresentada. A ausência de precipitação em quantidade, intensidade e com distribuição suficiente para o abastecimento dos cursos d'água e os lençóis freáticos pode ocorrer como no estágio atual com a falta d'água, tanto no meio rural como no meio urbano, pela inconstância da disponibilidade de água. Tatagiba et al. (2016) mencionam que o déficit hídrico na estação de seca no Espirito Santo afeta negativamente as taxas fotossintéticas em plantações de eucalipto.

Os meses que compõem a estação chuvosa nas duas relações são: janeiro, março, outubro, novembro e dezembro. Com o mês de fevereiro ocorre como mencionado acima, é um mês da estação chuvosa pela relação PM75/PA75. Observa-se que a relação PM/PA apresenta maiores porcentagens (cor vermelha) nos meses chuvosos quando comparado com os PM75/PA75 (cor 


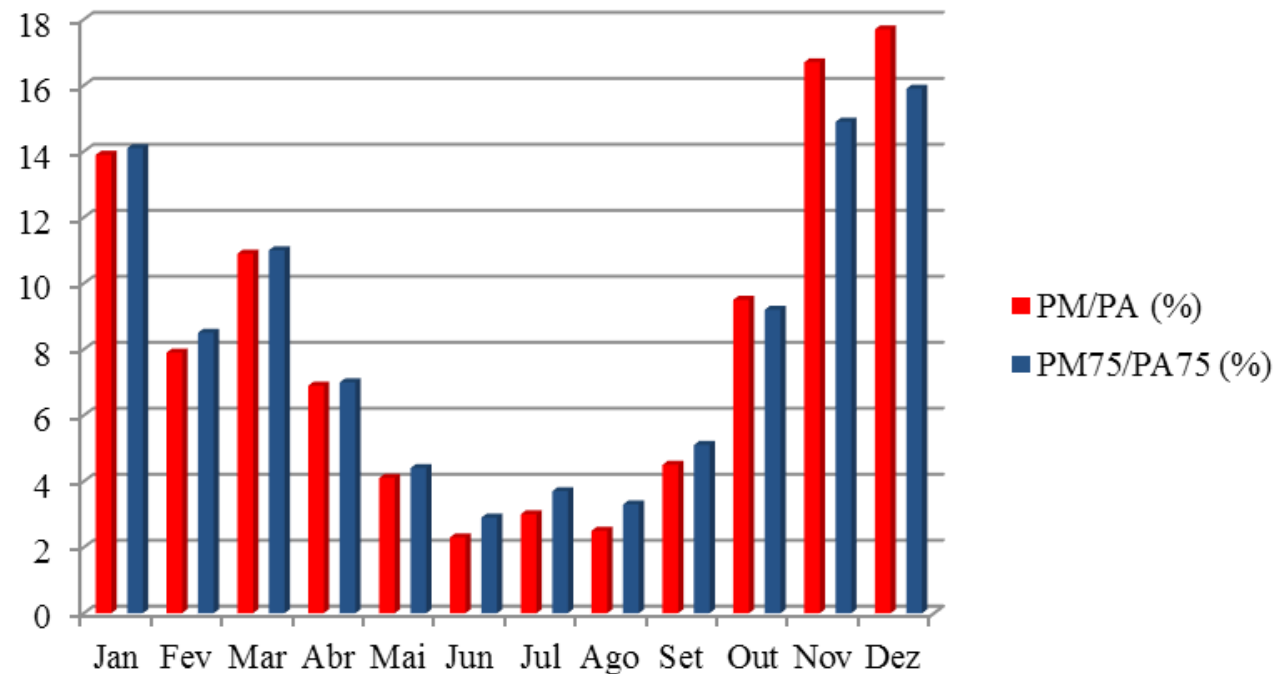

Figura 2. Apresentação dos meses que compõem a estação de seca e chuvosa.

azul) (Figura 2). O inverso corre para os meses da estação de seca, ou seja, maiores porcentagens para PM75/PA75. A relação PM/PA é mais restritiva nos meses de junho, julho e agosto e a relação PM75/ PA75 é mais restritiva para outubro, novembro e dezembro. Este comportamento vem confirmar o problema de consistência abordado por Mousinho et al. (2006), Blain et al. (2007) e Lima et al. (2008) de se utilizar a média para o ordenamento das atividades agrícolas. Marcuzzo (2014) considerou no estudo da distribuição espacial da precipitação no Mato Grosso o índice de anomalia de chuva (IAC) para determinação de período de seca e de chuva, encontrando resultados satisfatórios por esse método, que pode auxiliar no monitoramento para prognósticos e diagnósticos da variação pluviométrica e climatológica regional.

Segundo Mello et al. (2012), o estado do Espirito Santo apresenta dois períodos de ocorrência da precipitação pluvial média, um chuvoso que compreende os meses de outubro a março (verão), e outro seco, com totais médios mensais inferiores a $30 \mathrm{~mm}$, entre abril e setembro (inverno). Entretanto, Uliana et al. (2013) determinaram com $75 \%$ de probabilidade, para o Espirito Santo, a ocorrência provável das maiores precipitações nos meses de novembro e dezembro e as menores de junho a agosto. Cabe ressaltar que, apesar de usarem metodologias distintas para estudar a distribuição espacial da precipitação no Espirito
Santo, observa-se que as maiores e menores precipitações ocorrem quase sempre nos mesmos meses do ano.

O Quadro 2 apresenta os dados da análise de dependência espacial dos percentis 75 da precipitação nos 12 meses do ano para o estado do Espírito Santo.

O modelo de semivariograma de maior ocorrência no ajuste foi o esférico para os percentis 75 da precipitação pluvial mensal no Espirito Santo, assim como também no estudo de Silva et al. (2011b). Segundo Trangmar et al. (1985), a escolha de um modelo deve ser criteriosa, pois cada um fornece seus parâmetros que influenciam na interpolação de valores para locais onde não se realizou as medições. Neste caso, as correlações entre os valores observados e os estimados pela validação cruzada foram significativas $(p<0,05)$, com o coeficiente (r-vc) variando entre 36,4 a $81,4 \%$.

O alcance de dependência espacial (a) é tido como o principal parâmetro fornecido pela geoestatística, que representa a distância em que uma variável apresenta continuidade espacial. Sendo que, a partir desta distância, o comportamento espacial da variável passa a ser totalmente aleatório (LEMOS FILHO et al., 2008). O menor alcance (a) de dependência espacial foi obtido para os meses de março e abril $(46,1 \mathrm{~km})$ com o modelo esférico no ajuste, indicando assim 
Quadro 2. Modelos e parâmetros dos semivariogramas ajustados aos dados de precipitação pluvial dos percentis 75 no estado do Espírito Santo

\begin{tabular}{cccccc}
\hline Mês & Modelo & $\mathrm{a}(\mathrm{km})$ & $\mathrm{R}^{2}(\%)$ & IDE $(\%)$ & $\mathrm{r}$-vc (\%) \\
\hline Jan & Esf & 120,8 & 50,4 & 56,2 & 52,6 \\
Fev & Esf & 56,8 & 64,6 & 99,9 & 74,0 \\
Mar & Esf & 46,1 & 73,4 & 99,9 & 74,0 \\
Abr & Esf & 46,1 & 73,4 & 99,9 & 80,0 \\
Mai & Gaus & 112,4 & 76.9 & 79,2 & 81,4 \\
Jun & Gaus & 190,0 & 92,1 & 79,1 & 75,4 \\
Jul & Esf & 139,3 & 91,2 & 99,9 & 60,0 \\
Ago & Gaus & 121,8 & 94,6 & 88,6 & 74,7 \\
Set & Esf & 143,6 & 89,2 & 99,9 & 78,2 \\
Out & Esf & 210,6 & 80,4 & 83,5 & 56,9 \\
Nov & Exp & 57,9 & 53,6 & 83,9 & 36,4 \\
Dez & Esf & 62,0 & 83,6 & 99,9 & 60,0 \\
\hline
\end{tabular}

Esf: modelo esférico; Gaus: modelo gaussiano; Exp: modelo exponencial; a: alcance (km); IDE: índice de dependência espacial (\%); $\mathrm{R}^{2}$ : coeficiente de determinação (\%); e r-vc: coeficiente de correlação da validação cruzada (\%)

o mesmo padrão de distribuição espacial apesar destes meses não fazerem parte da mesma estação de chuva, pelos critérios estabelecidos.

Os dois maiores alcances foram encontrados nos meses de junho $(190,0 \mathrm{~km})$ e outubro $(210,6 \mathrm{~km})$, com modelo gaussiano e esférico, respectivamente. A maior continuidade espacial da precipitação dos percentis 75 está relacionada com os maiores alcances, ou seja, com maior número de pontos vizinhos localizados neste raio de ação, contribuindo para maior precisão na estimativa da precipitação pluvial para locais onde não se tem postos pluviométricos. Uliana et al. (2013) também encontraram no mês de outubro o maior alcance para a ocorrência de $75 \%$ da maior precipitação no estado com ajuste para o modelo gaussiano.

Mello et al. (2012) encontraram os maiores alcances para os meses mais chuvosos no Espirito Santo, com ajuste ao modelo exponencial, no seu estudo da distribuição espacial da precipitação média mensal. Silva et al. (2011a) encontraram para a precipitação média mensal alcances de dependência espacial de $54 \mathrm{~km}$, para o mês de junho, $80 \mathrm{~km}$ para outubro e novembro e $111 \mathrm{~km}$ para os demais meses, no Espirito Santo, quando utilizaram 110 postos pluviométricos. Silva et al. (2011b) estudaram a variabilidade espacial da precipitação média mensal encontrando $45,7 \mathrm{~km}$ de alcance para o Espirito Santo. Quando esses autores consideraram as coordenadas geográficas e as altitudes dos postos pluviométricos definindo na análise multivariada uma componente principal que foi utilizada como covariável (cokrigagem) para estimar a precipitação média obtevese um alcance de $300 \mathrm{~km}$, mostrando relação espacial da precipitação com altitude dos postos pluviométricos.

$O$ índice de dependência espacial (IDE) apresentou forte continuidade para todos os meses (IDE $\geq 75 \%$ ), com exceção do mês de janeiro, cuja dependência é moderada, segundo classificação apresentada por Zimback (2001).

Os mapas da distribuição espacial dos percentis 75 da precipitação pluvial mensal foram construídos por krigagem ordinária $(\mathrm{KO})$ e estão representados nas Figuras 3, 4 e 5. Os mapas apresentam a variabilidade espacial e a regionalização dos percentis 75 da precipitação mensal no Espirito Santo. Silva et al. (2011a) comparam o método de interpolação krigagem ordinária (KO) com o inverso da distância até a sexta potencia (IDW) e concluíram que a $\mathrm{KO}$ foi superior na construção dos mapas de precipitação média para todos os meses no Espírito Santo. Segundo estes autores a KO é indicada para a aplicação em regiões onde a distribuição espacial dos dados observados é boa e sem descontinuidades significativas.

$\mathrm{O}$ mês de janeiro (Figura 3A) mostra a precipitação do percentil 75 maior que $265 \mathrm{~mm}$ ao longo de todo o estado. Na região sudoeste, em torno do Parque Nacional do Caparaó, apresenta 
a ocorrência de precipitação maior que $300 \mathrm{~mm}$, região das maiores altitude na topografia do estado. Uliana et al. (2013) afirmam que as maiores precipitações mensais e anuais provável $(75 \%$ de ocorrência) estão presentes nas maiores altitudes, e este comportamento demonstra que apesar das características tropicais presentes no estado a altitude torna-se um influente controle climático, impondo-se ao fator latitudinal.

No mês de fevereiro (3B) as maiores precipitações se encontram na faixa de 160 a 195 $\mathrm{mm}$ na região sul e no entorno do Parque Nacional do Caparaó, identificando diminuição razoável de ocorrência em relação ao mês de janeiro, o que coloca este mês na interseção da estação chuvosa com a de seca. Em maior área do estado, acima do vale do Rio Doce, ocorrem precipitações entre 125 a $160 \mathrm{~mm}$, como se observa para o mês de março (Figura 3C). No mês de abril (Figura 3D), as maiores precipitações se concentram acima de $95 \mathrm{~mm}$ na região sul, sudeste e nordeste do estado.
As Figuras 4 (A, B, C e D) e Figura 5A mostram a ocorrência da precipitação dos percentis 75 nos meses que compõem a estação de seca, que de uma forma geral, verifica-se maior continuidade espacial em cada um dos meses no sentido do sul para norte e vice-versa e, no entanto, maior variabilidade espacial da direção oeste-leste em função das cadeias de montanhas que compõem a paisagem de Minas Gerais para o litoral capixaba. O Atlas de ecossistemas do Espírito Santo (2008) apud Uliana et al. (2013) afirma que as maiores precipitações do estado tendem a ocorrer nas frentes acidentadas para o mar, onde as massas de ar vindas do mar carregadas de umidade resfriam-se, condensam-se e precipitam como chuvas. Nas partes de menor altitude, em particular nas situadas mais adentro do estado, ao longo do Rio Doce, divisa com Minas Gerais e vale do Itapemirim, todas protegidas por elevações entre elas e o mar, as precipitações são bem menores.
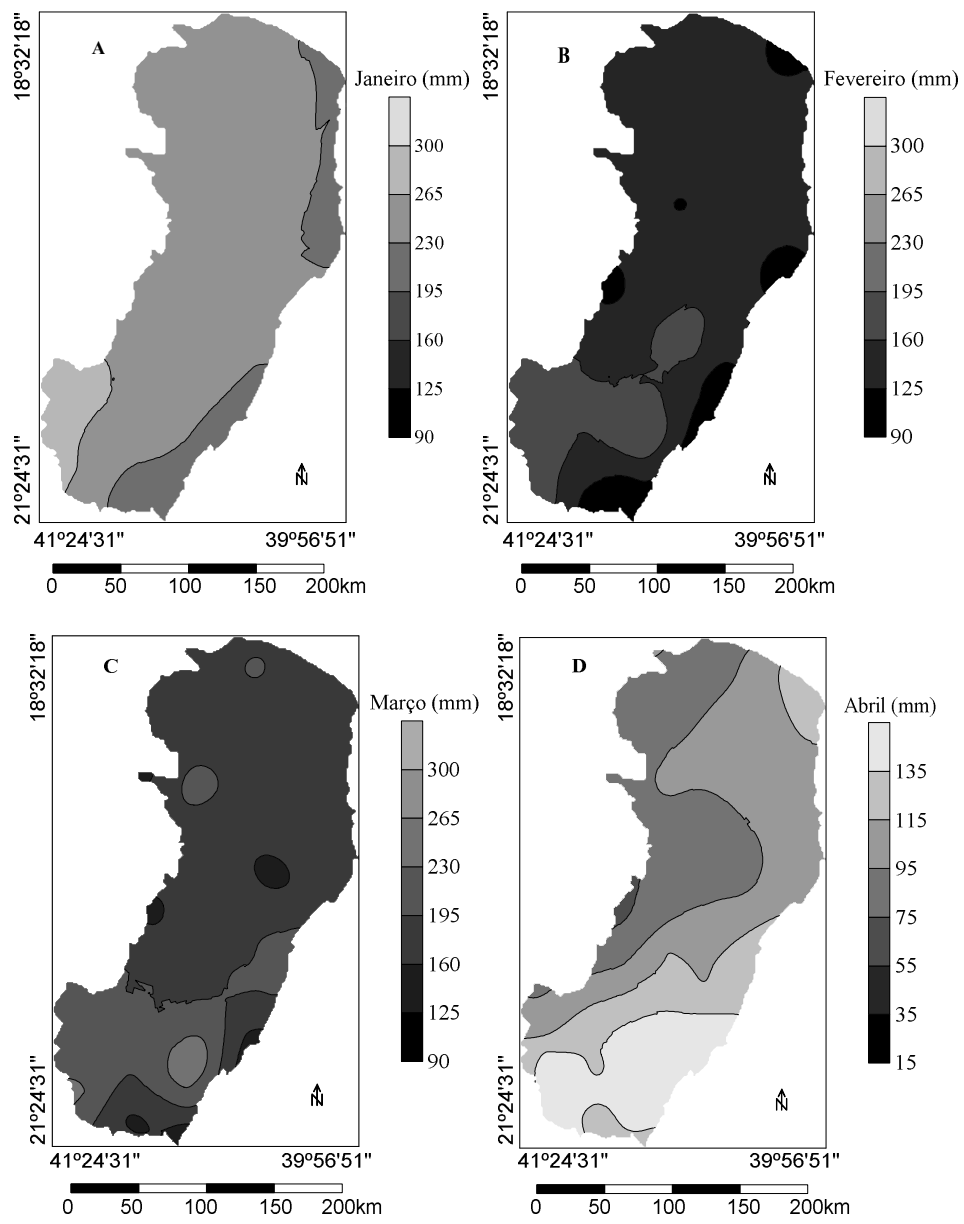

Figura 3. Mapas da distribuição espacial dos percentis 75 para os meses de janeiro (A), fevereiro (B), março (C) e abril (D). 

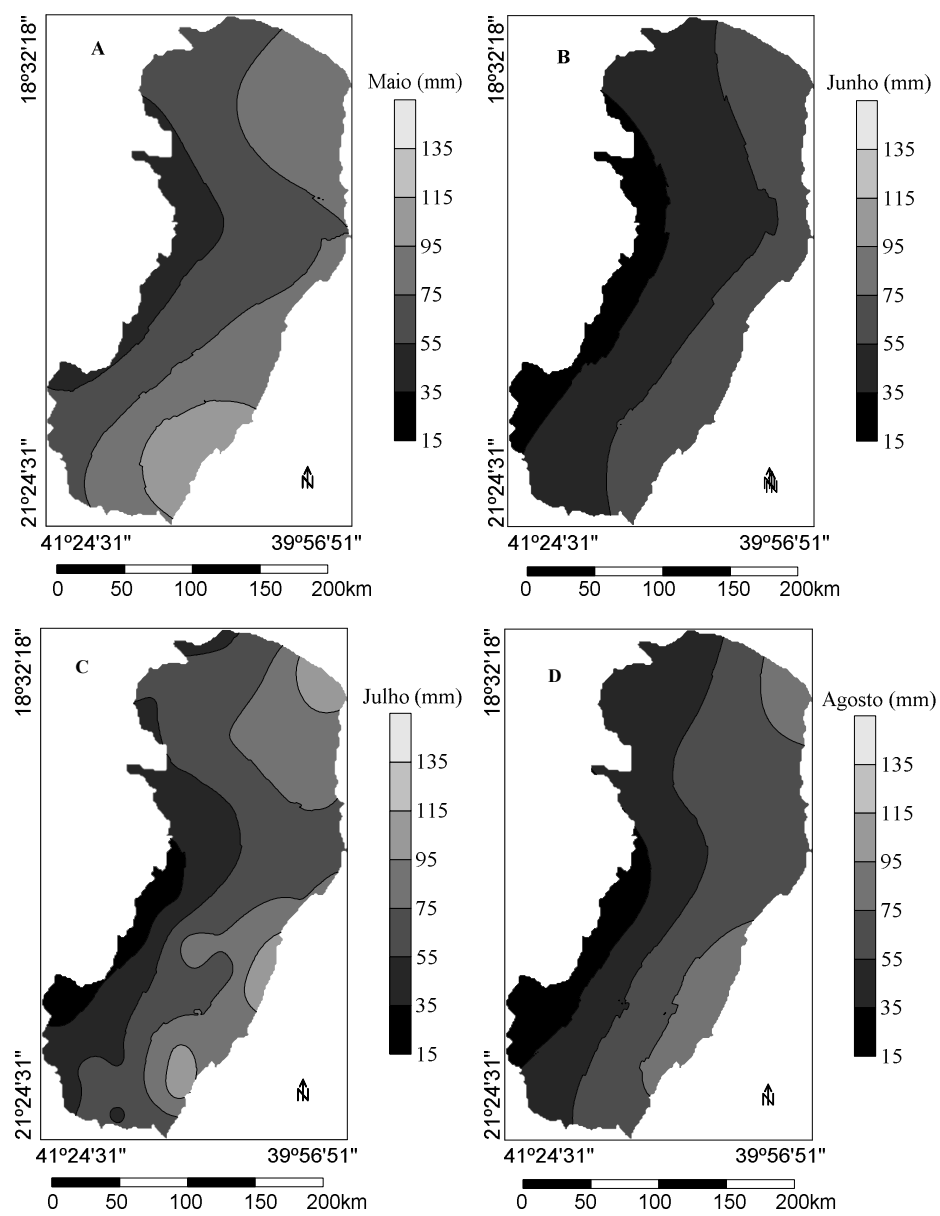

Figura 4. Mapas da distribuição espacial dos percentis 75 para os meses de maio (A), junho (B), julho (C) e agosto (D).

Nos meses de maio e agosto, não ocorre precipitação maior que $95 \mathrm{~mm}$ (percentil 75), sendo as maiores ocorrências nas regiões litorâneas que vai diminuindo à medida que caminha para o interior na direção da divisa com Minas Gerais, como discutido anteriormente.

As menores precipitações ocorrem nos meses de junho, julho, agosto e setembro na classe de 15 a $35 \mathrm{~mm}$ (percentil 75), mostrando ser nesses meses a menor disponibilidade hídrica no solo para se desenvolver as práticas agrícolas. Os municípios que fazem divisa com Minas Gerais apresentam os valores de precipitação mensal dos percentis 75 aumentando a partir da divisa para o litoral, mostrando certa semelhança entre os meses quanto à forma de distribuição espacial da precipitação pluvial.

A estação de seca é mais proeminente nos municípios que compõem a região noroeste do estado. As maiores ocorrências da precipitação $(\mathrm{mm})$ nos meses de seca aparecem na região do litoral sul e nordeste do Espírito Santo. O mês de junho é o mais critico, pois não apresenta ocorrência de precipitação maior que $75 \mathrm{~mm}$, do percentil 75, em nenhuma região do estado. Segundo Reboita et al. (2010) esse fato deve-se à presença de umidade oriunda do oceano Atlântico, mas que, devido à intensificação do Anticiclone do Atlântico Sul na direção oeste fica restrita à faixa litorânea, fazendo com que no Estado do Espírito Santo tenha um período seco mais característico na sua faixa oeste.

$\mathrm{Na}$ Figura 5B, no mês de outubro ocorre presença da zona de convergência de umidade, em relação ao mês de setembro (Figura 5A), verificase aumento de precipitação na região norte do estado, o que leva no mês de outubro a divisão do estado em relação à ocorrência da precipitação. As maiores precipitações ocorrem no sentido do sul e as menores do meio para o norte, região onde se localiza o vale do Rio Doce. 
No mês de novembro (Figura 5C), há precipitações em todo o estado entre 195 a 300 $\mathrm{mm}$ dos percentis 75 . Já nos meses de dezembro (Figura 5D) e janeiro (Figura 3A) evidenciam maiores precipitações nas regiões central, serrana e no entorno do Parque Nacional do Caparaó, com eventos maiores que $265 \mathrm{~mm}$ perfazendo uma área maior que a metade do estado. Este fato ocorre possivelmente em função dos ventos úmidos vindos do litoral, zona de convergência do atlântico sul, e do seu encontro com as cadeias de montanha (CARVALHO; ASSAD, 2005). Silva et al. (2011a) afirmam que o clima no estado é influenciado, de maneira marcante, pela topografia e pela exposição das encostas, condicionadoras de chuvas orográficas, associadas à proximidade do oceano.

Nota-se que, para o agricultor do estado desenvolver suas atividades utilizando melhor a água no ciclo vegetativo das culturas, têm-se os três meses consecutivos mais chuvosos, que são novembro, dezembro e janeiro, respectivamente, com contribuição de $47,3 \%$ na precipitação anual média acumulada e de $44,9 \%$ para o percentil 75. As práticas agrícolas de preparo mecanizado do solo, normalmente, são iniciadas na estação chuvosa, como reforma de pastagens e plantio de novas culturas. Cabe ressaltar que, se essas práticas não forem realizadas segundo critérios conservacionistas, pode levar perda de solo expressiva por erosão hídrica devido a maior erosividade nesses respectivos meses. Mello et al. (2012) mostraram que no Espirito Santo o mês de dezembro é o mais chuvoso e com maior erosividade média, em todas as regiões, seguido por novembro e janeiro devido a maior ocorrência de precipitação média.

Segundo Lima et al. (2008), a utilização dos valores médios de precipitação nos meses que apresentam valores discrepantes deve ser feita de
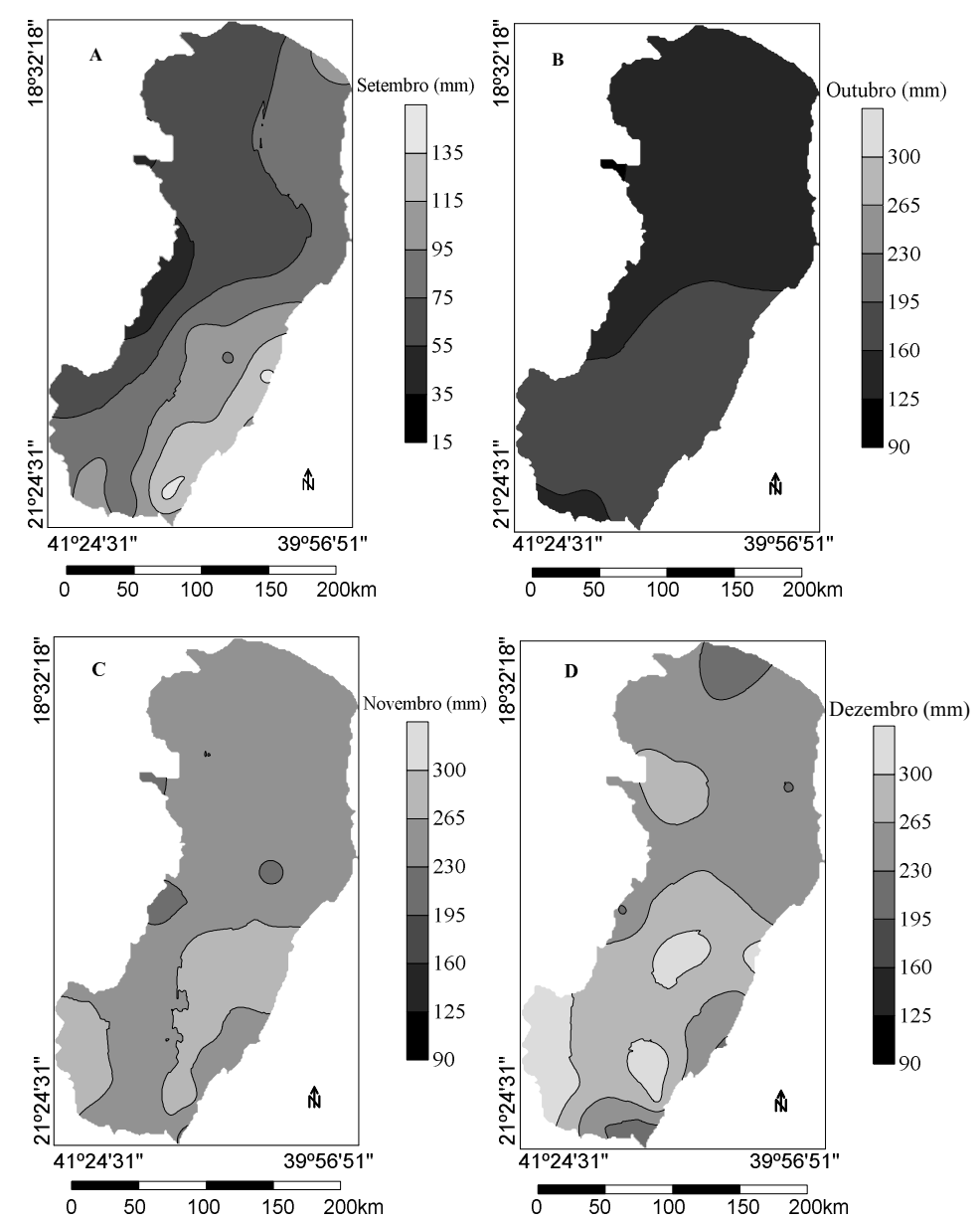

Figura 5. Mapas da distribuição espacial dos percentis 75 para os meses de setembro (A), outubro (B), novembro (C) e dezembro (D). 
modo extremamente criteriosa para o planejamento da agricultura irrigada, para estudos de zoneamento climático ou para realização de zoneamento de riscos, pois a alta variação da lâmina precipitada pode levar a erros grosseiros de planejamento, trazendo prejuízos sérios devido aos altos déficits hídricos que podem ocorrer e não estarem previstos nos estudos.

A distribuição espacial e temporal mensal dos percentis 75 confirma a presença de microclimas no estado, nos diferentes meses, informação essa essencial a ser seguida para o planejamento agrícola.

\section{CONCLUSÃO}

- O estado do Espírito Santo apresenta regiões de seca e de chuva bem definidas, sendo que os meses abril, maio, junho, julho, agosto e setembro caracterizam a estação de seca. Os meses de dezembro, novembro e janeiro apresentam as ocorrências das maiores lâminas de precipitação nas regiões: serrana, litoral sul e no Parque Nacional do Caparaó;

- Os percentis 75 da precipitação pluvial mensal apresentam forte dependência espacial, com exceção no mês de janeiro, sendo que os alcances de dependência espacial variam de 41,6 a $210,6 \mathrm{~km}$ entre os meses; e

- A distribuição espacial dos percentis 75 da precipitação pluvial evidenciou diferentes microclimas no estado, mostrando que os municípios que compõem a região noroeste como os de menor ocorrência de lâmina de precipitação, principalmente no mês de junho.

\section{AGRADECIMENTO}

Ao CNPq pela bolsa de produtividade concedida ao primeiro autor (Processo: 308505/2013-1).

\section{REFERÊNCIAS BIBLIOGRÁFICAS}

ANDRADE, A.R.; NERY, J.T. Análise sazonal e espacial da precipitação pluvial na bacia hidrográfica do Rio Ivaí - Paraná. Boletim de Geografia, Maringá. v.29, n.2, p.107-121, 2011.
Disponível em: <http://periodicos.uem.br/ojs/ index.php/BolGeogr/article/viewFile/8648/9040 >. Acesso em 15/09/2016.

BLAIN, G.C.; KAYANO, M.T; CAMARGO, M.B.P.; LULU, J. Variabilidade amostral das séries mensais de precipitação pluvial em duas regiões do Brasil: Pelotas-RS e Campinas-SP. Revista Brasileira de Meteorologia, v.24, n.1, p.1-11, 2009. Disponível em: $<$ http://www.producao.usp.br/ handle/BDPI/11488>. Acesso em: 03/08/2016.

BLAIN, G.C.; PIEDADE, S.M.S.; CAMARGO, M.B.P.; GIAROLLA, A. Distribuição temporal da precipitação pluvial mensal observada no posto meteorológico do Instituto Agronômico. Bragantia, v.66, n.02, p.347-355. 2007. Disponível em: $<$ http://www.scielo.br/scielo.php?script=sci arttex t\&pid=S0006-87052007000200019 $>$. Acesso em: 03/08/16.

BRITTO, F.P.; BARLETTA, R..; MENDONÇA, M. Variabilidade espacial e temporal da precipitação pluvial no Rio Grande do Sul: Influencia do fenômeno El Niño oscilação Sul. Revista Brasileira de Climatologia. v.8, n.3, p.38-48. 2008. Disponivel em: < https://www. researchgate.net/publication/277195019>. Acesso em: 02/082016

CARGNELUTTI FILHO, A.; MATZENAUER, R.; RADIN, B.; MALUF, J.R.T.; HAUSER, L. Dimensionamento da amostra para a estimação da média de precipitação pluvial mensal em diferentes locais do Estado do Rio Grande do Sul. Ciência Rural, v.40, n.1, p.12-19. 2010. Disponível em: $<$ http://www.scielo.br/scielo.php?script=sci arttext\&pid $=$ S0103-84782010000100003\&lng $=$ en \&nrm $=$ iso $>$. Acesso em: 30/08/2016.

CARVALHO, J.R.P.; ASSAD, E.D. Análise espacial da precipitação pluviométrica no Estado de São Paulo: Comparação de métodos de interpolação. Engenharia Agrícola, v.25, n.02, p.377- 384. 2005. Disponível em: < https://www. researchgate.net/publication/272708341 $>$. Acesso em 15/09/2016. 
GURGEL, H.C. Variabilidade espacial e temporal do NDVI sobre o Brasil e suas conexões com o clima. 2003. 120f. Dissertação (Mestrado em Sensoriamento Remoto) - Instituto Nacional de Pesquisas Espaciais (INPE). São José dos Campos. 2003.

LEMOS FILHO, L.C.A.; OLIVEIRA, E.L.; FARIA, M.A.; ANDRADE, L.A.B. Variação espacial da densidade do solo e matéria orgânica em área cultivada com cana-de-açúcar (Saccharum officinarum L.). Revista Ciência Agronômica, v.39, n.02, p.193-202. 2008. Disponível em: < http:// www.ccarevista.ufc.br/seer/index.php/ccarevista/ article/view/47>. Acesso em 30/08/2016.

LOPES, R.M.; CARVALHO, L.F.M.; LIMA, A.M.; MARIANO, Z.T. Variabilidade espacial e temporal das chuvas no baixo curso do rio claro- GO, no período de 1977 a 2010. Revista Geonorte, Edição Especial, v.2, n.4, p.1126-1137, 2012. Disponível em: $\quad$ www.periodicos.ufam.edu.br/index.php/ revista-geonorte/article/view/2167>. Acesso em: 04/08/2016.

LIMA, J.S.S.; SILVA, S.A.; OLIVEIRA, R.B.; CECÍLIO, R.A.; XAVIER, A.C. Variabilidade temporal da precipitação mensal em Alegre-ES. Revista Ciência Agronômica, v.39, n.02, p.327332. 2008. Disponível em: $<$ www.ccarevista.ufc. br/seer/index.php/ccarevista/article/view/67>. Acesso em 30/08/2016.

MARCUZZO, F.F.N. Distribuição espacial da sazonalidade da precipitação pluviométrica no mato grosso do sul e estudo de anomalias interanual. ACTA Geográfica, v.8, n.16, p.22-39. 2014. Disponível em: $<$ http://revista.ufrr.br/index. php/actageo/article/view/1366 >. Acesso em: 03/08/2016.

MARCUZZO, F.F.N.; ANDRADE, L.R.; MELO, D.C.R. Métodos de Interpolação Matemática no Mapeamento de Chuvas do Estado do Mato Grosso. Revista Brasileira de Geografia Física, v.4, n.4, p.793-804, 2011. Disponível em: $<$ http://www. revista.ufpe.br/rbgfe/index.php/revista/article/ view/197/204>. Acesso em 15/09/2016.
MARCUZZO, F.F.N.; CARDOSO, M.R.D. ; MELLO, L.T.A. Uso dos Métodos de Krigagem e Spline de Tensão no Mapeamento de Chuvas na Região Metropolitana de Goiânia e Seu Entorno. In: II Simpósio Internacional Caminhos Atuais da Cartografia na Geografia, 2010, São Paulo. Anais do II Simpósio Internacional Caminhos Atuais da Cartografia na Geografia. São Paulo: EDUSP, v.1. p.128-128. 2010. Disponível em $<\underline{\text { http://www.cprm.gov.br/publique/ }}$ media/Evento_Uso_Marcuzzo.pdf $>$. Acesso em 15/09/2016.

MELLO, C.R.; VIOLA, M.R.; CURI, N.; SILVA, A.M.. Distribuição espacial da precipitação e da erosividade da chuva mensal e anual no estado do Espírito Santo. RevistaBrasileiradeCiênciadoSolo, Viçosa-MG, v.36, p.1878-1891. 2012. Disponível em: $\quad<$ http://www.scielo.br/scielo.php?script $=$ sci arttext\&pid $=$ S0100-06832012000600022 $>$. Acesso em: 03/08/2016.

MELO JÚNIOR, J.C.F., SEDIYAMA, G.C., FERREIRA, P.A., LEAL, B.G., MINUSI, R.B. Distribuição espacial da frequência de chuvas na região hidrográfica do Atlântico, Leste de Minas Gerais. Revista Brasileira de Engenharia Agrícola e Ambiental, Campina Grande-PB, v.10, n.02, p.417-425. 2006. Disponível em: < http://www. scielo.br/pdf $/ \% 0 \mathrm{D} / \mathrm{rbeaa} / \mathrm{v} 10 \mathrm{n} 2 / \mathrm{v} 10 \mathrm{n} 2 \mathrm{a} 24 . \mathrm{pdf}>$. Acesso em: 20/04/2016.

NERY, J.T.; ALVES, R.T. Variabilidade da precipitação pluvial na UGRH do Médio Paranapanema, Estado de São Paulo. Acta Scientiarum, Maringá-PR, v.31, n.01, p.93102, 2009. Disponível em: <https://www. researchgate.net/publication/26626924>. Acesso em 20/04/2016.

NERY, J.T.; MARTINS, M.L.O.F.; SANT'ANA, J.L.N. Variabilidade da precipitação no Brasil Meridional. Acta Scientiarum, Maringá-PR, v.24, n.6, p.1687-1695. 2002. Disponível em: $<$ http:// eduem.uem.br/ojs/index.php/ActaSciTechnol/ article/viewFile/2501/1566>. Acesso em: 20/04/2016. 
REBOITA, M.S.; GAN, M.A.; ROCHA, R.P.; AMBRIZZI, T. Regimes de precipitação na América do Sul: uma revisão bibliográfica. Revista Brasileira de Meteorologia, v.25, n.2, p.185-204, 2010. Disponível: $<$ http://www.scielo. $\mathrm{br} / \mathrm{pdf} / \mathrm{rbmet} / \mathrm{v} 25 \mathrm{n} 2 / \mathrm{a} 04 \mathrm{v} 25 \mathrm{n} 2 . \mathrm{pdf}>$. Acesso em: 15/09/2016.

SARTORI, A.A.C.; SILVA, A.F.; RAMOS, C.M.C.; ZIMBACK, C.R.L. Variabilidade temporal e mapeamento dos dados climáticos de Botucatu-SP. Irriga, Botucatu-SP, v.15, n.2, p.131-139. 2010. Disponível em: $<$ http://home. ufam.edu.br/rogeo/pibic024/Sartori_etal_2010 variabilidadeTempGeoest.pdf $>$. Acesso em: 04/08/2016.

SENNA, R.S.; XAVIER, A.C.; LIMA, J.S.S.; CECÍLIO, R.A. Metodologias para estimativa dos parâmetros da equação de chuvas intensas no estado do Espírito Santo. Engenharia na Agricultura, Viçosa-MG, v.18, n.6, p.496-503. 2010. Disponível em: <http://www.seer.ufv.br/ seer/index.php/reveng/article/viewFile/85/141>. Acesso em: 15/09/2016.

SILVA, K.R.; CECÍLIO, R.A.; XAVIER, A.C.; PEZZOPANE, J.R.M.; GARCIA, G.O. Interpolação espacial da precipitação no estado do Espírito Santo. Floresta e Ambiente, v.18, n.4, p.417-427. 2011a. Disponível em: <http://www. floram.org/files/v18n4/v18n4a8.pdf> $>$. Acesso em: 03/08/2016.

SILVA, S.A.; LIMA, J.S.S. Número de postos pluviométricos necessários para a estimativa da precipitação mensal no estado do Espírito Santo, Brasil. Revista Brasileira de Meteorologia, v.26, n.4, p. 555-560, 2011. Disponível em 15/09/2016. $<$ http://www.scielo.br/pdf/rbmet/v26n4/a05v26n4. pdf>. Acesso em 15/09/2016.

SILVA, S.A.; LIMA, J.S.S.; BOTTEGA, E.L. Variabilidadeespacial daprecipitaçãopluviométrica para o Estado do Espírito Santo utilizando métodos multivariados. Revista Brasileira de Ciências Agrárias, v.06, n.04, p.703-709. 2011b.

TATAGIBA, S.D.; PEZZOPANE, J.E.M; REIS, E.F. Fotossintese em eucalyptus sob diferentes condições edafoclimáticas. Engenharia na Agricultura, v.23, n.04, p.336-345. 2016. Disponível em: $<$ www.seer.ufv.br/seer/index. php/reveng/article/view/573/394>. Acesso em: 30/08/2016.

TORMAN, V.B.L.; COSTER, R.; RIBOLDI, J. Normalidade de variáveis: métodos de verificação e comparação de alguns testes não-paramétricos por simulação. Revista HCPA, v.32, n.2. p.227234. 2012. Disponível em: $<$ http://seer.ufrgs.br/ hcpa/article/viewFile/29874/19186>. Acesso em 04/08/2016.

TRANGMAR, B.B.; YOST, R.S.; UEHARA, G. Applicattion of geostatistics to spatial studies of soil properties. Advances in Agronomy, San Diego, v.38, p.45-94. 1995. Disponível em: $<$ https://www. researchgate.net/publication/235257021>. Acesso em: 30/08/2016.

ULIANA, E.M.; REIS, E.F.; SILVA, J.G.F.; XAVIER, A.C. Precipitação mensal e anual provável para o estado do Espírito Santo. Irriga, Botucatu, v.18, n.1, p.139-147. 2013. Disponível em: $\quad<$ http://irriga.fca.unesp.br/index.php/irriga/ article/view/493/344>. Acesso em: 15/09/2016.

YAMAMONTO, J.K.; LANDIM, P.M.B. Geoestatística: conceitos e aplicações. Ed. Oficina de Texto. 215p. 2013.

ZIMBACK, C.R.L. Análise espacial de atributos químicos de solos para fins de mapeamento da fertilidade. 2001. 114f. Tese de Livre- Docência (Livre-Docência em Levantamento do solo e fotopedologia) - Faculdade de Ciências Agrarias/ UNESP. Botucatu-SP. 2001. 